\title{
Relationship between blood pressure measurements recorded on patients' charts in family physicians' offices and subsequent 24 hour ambulatory blood pressure monitoring
}

\author{
Marshall Godwin*1, Dianne Delva1 ${ }^{1}$, Rachelle Seguin ${ }^{1}$, Ian Casson ${ }^{1}$, \\ Susan MacDonald1, Richard Birtwhistle ${ }^{1}$ and Miu Lam ${ }^{1,2}$
}

Address: ${ }^{1}$ Centre for Studies in Primary Care and the Department of Family Medicine, Queen's University, 220 Bagot Street, Kingston, Ontario, Canada. K7L 5E9 and 2Centre for Studies in Primary Care and the Department of Community Health and Epidemiology, Queen's University, Kingston, Ontario, Canada

Email: Marshall Godwin* -godwinm@post.queensu.ca; Dianne Delva - mdd2@post.queensu.ca; Rachelle Seguin - seguinr@post.queensu.ca; Ian Casson - ric@post.queensu.ca; Susan MacDonald - sem@post.queensu.ca; Richard Birtwhistle - birtwhis@post.queensu.ca;

MiuLam-lamm@post.queensu.ca

* Corresponding author

Published: 29 March 2004

BMC Cardiovascular Disorders 2004, 4:2

This article is available from: http://www.biomedcentral.com/|47|-226I/4/2

(c) 2004 Godwin et al; licensee BioMed Central Ltd. This is an Open Access article: verbatim copying and redistribution of this article are permitted in all media for any purpose, provided this notice is preserved along with the article's original URL.
Received: 28 August 2003
Accepted: 29 March 2004

\begin{abstract}
Background: In most western countries $20 \%$ of adults have hypertension. Reports in the literature suggest that from 31 to $86 \%$ of treated patients are not at recommended target levels. However it is important to consider how we are determining whether targets are unmet and the degree to which they are unmet. Our underlying hypothesis is that white coat effect is partially responsible for the reported low rates of control of hypertension by primary care practitioners.

Methods: The study population consists of II42 patients who are being assessed for enrolment in two community-based randomized controlled trials. Patients must have essential hypertension, be on antihypertensive medication, and must not have met their blood pressure targets. We are reporting on the proportion of patients who have not achieved target, and the degree to which they have not achieved their target. We also report on the mean daytime blood pressures on 24 hour ABPM and compare these to mean blood pressures found on the patients' charts.

Results: We identified 3284 patient charts of patients with hypertension. Of these, I I 42 were determined to be "out of control" (did not achieve target) and 436 agreed to undergo 24 hour ABPM for final determination of eligibility. Overwhelmingly (95.8\% of the time) it was the systolic blood pressure that was not under control. However, most of the patients who had not achieved target according to our criteria were within $10 \mathrm{mmHg}$ of the recommended targets. Isolated systolic blood pressure was the best predictor of elevated mean daytime blood pressure on 24 hour ABPM.

Conclusions: At least $35 \%$ of patients had not achieved target blood pressure levels and this is primarily due to lack of control of systolic blood pressure. The best predictor of continuing hypertension on 24 hour ABPM was the mean systolic blood pressure on the patients chart. However, only $69 \%$ of patients who were uncontrolled according blood pressures recorded in the chart were uncontrolled according to 24 hour ABPM criteria. This suggests that the white coat effect makes blood pressure measurements in the doctor's offices, at least as currently done, not sufficiently accurate for determining treatment endpoint.
\end{abstract}




\section{Background}

Twenty percent of adults in Canada are hypertensive according to the Canada Health Surveys conducted between 1986 and 1992. [1] This constitutes about 4.3 million people. These numbers are similar to other countries where similar population surveys have been done [2] : France $22.1 \%$, UK 37.8\%, USA 20.1\%. While it is lower than reported in other countries [2] : Spain 68.3\% and Tawain $42 \%$.

Of the 4.3 million adults in Canada with hypertension, $57 \%$ are aware of the diagnosis, $34 \%$ are being treated, and $13 \%$ are treated and controlled. Therefore, of the $1,426,000$ being treated, only 559,000(39\%) have achieved target $(<140 / 90)$ and $867,000(61 \%)$ are not under adequate control [2]. These estimates of blood pressure control are similar to those reported in France and Spain, better than the UK, but not as good as those reported in the USA. He et al [3] recently calculated that poor blood pressure control was responsible for 62,000 unnecessary deaths each year in the UK.

Hypertension is an important risk factor for all major atherosclerotic cardiovascular disease outcomes, including cardiac failure, stroke, coronary artery disease, and peripheral vascular disease [4]. So why are we doing so poorly? Are the results any better if we look at clinical practice information rather than population data? In 2001 Seddon [5] conducted a systematic review of studies of quality of clinical care in general practice in the UK, Australia, and New Zealand. In the 11 papers related to care of hypertension in clinical practice, $51-64 \%$ of people with hypertension were being treated and of those being treated between 31 and $83 \%$ were controlled according to guidelines.

However it is important to consider the degree of "lack of control". In 2003, Amar [6] in a study of patients with hypertension and coronary disease found that while as many as $67 \%$ of patients were uncontrolled, over half of these were categorized as such because of borderline systolic blood pressure; their diastolic blood pressures were normal. Elevated systolic blood pressures were not treated as rigorously as elevated diastolic blood pressures.

In this paper we report the degree to which systolic vs diastolic blood pressure contribute to a determination of inadequate blood pressure control in family physicians' practices, and the accuracy of that determination when compared to the results of 24 hour ambulatory monitoring. An underlying hypothesis is that white coat effect is partially responsible for the reported low rates of control of hypertension by primary care practitioners.

\section{Methods}

The study population consists of 1142 who met the blood pressure criteria for being "out of control" through a review of the last three blood pressure measurements recorded on their family physician's charts. These patients were being recruited for enrollment into two randomized controlled trials of hypertension. One trial is testing the effect of home blood pressure monitors on blood pressure control; the other is looking at the effect of an intensive scheduled approach to medical management of hypertension. To be eligible to be enrolled in these trials patients must i) have a diagnosis of essential hypertension, ii) be receiving medications to treat their hypertension, and iii) not have achieved target levels of blood pressure.

The same enrollment process is used for both studies. First, a list of all hypertensive patients of a participating physician is generated. The charts of these patients are then reviewed for eligibility and to extract the last three blood pressure measurements on each chart. If the mean of the last three blood pressure measurements is above the target for the patient or if two of the last three measurements are above the target for the patient, then they are considered to be out of control. The target blood pressures are $<140 / 90 \mathrm{mmHg}$ except for diabetics where it is $<130 /$ $80 \mathrm{mmHg}$ and patients with renal insufficiency where it is $<125 / 75 \mathrm{mmHg}$. Patients who had not achieved their target were then requested to undergo 24 hour ambulatory blood pressure monitoring (ABPM).

If the mean daytime blood pressure on the $24 \mathrm{hr}$ ABPM assessment is greater than or equal to $135 \mathrm{mmHg}$ systolic or $85 \mathrm{mmHg}$ diastolic then the patient is eligible for the trial. We are using the TM-2430 A\&D Medical Ambulatory Blood Pressure Monitor, which has been clinically validated according to the British Hypertension Society protocols [7].

We are not reporting on the outcomes of the two trials as they are still in progress. Rather, using data collected at baseline, we describe the discrepancy between office blood pressure measurements and ABPM in patients who appear to have uncontrolled hypertension by office BP measurements. All patients considered for both studies regardless of group assignment are included.

\section{Results}

We identified 3284 patient charts of patients with hypertension from 44 family physician practices in the region of Kingston, Ontario, Canada. Of these, 1142 were determined to be "out of control" based on our criteria as described above and 436 agreed to undergo 24 hour ABPM for final determination of eligibility. 
Table I: Age, sex, mean BP by age, and the components of blood pressure measurement of I I 42 patients who had not achieved target levels.

\begin{tabular}{|c|c|c|}
\hline \multirow[t]{2}{*}{ Sex } & Female & $685(60 \%)$ \\
\hline & Male & 457 (40\%) \\
\hline \multirow[t]{3}{*}{ Age (years) } & Mean(SD) & $64(13)$ \\
\hline & Minimum & 22 \\
\hline & Maximum & 94 \\
\hline \multicolumn{2}{|c|}{ Diabetes } & $206(18 \%)$ \\
\hline \multicolumn{2}{|c|}{ Systolic BP not achieved target } & $1094(95.8 \%)$ \\
\hline \multicolumn{2}{|c|}{ Diastolic BP not achieved target } & $462(40.5 \%)$ \\
\hline \multicolumn{2}{|c|}{ Both systolic and diastolic not achieved target } & $414(36.3 \%)$ \\
\hline \multicolumn{2}{|c|}{ ONLY systolic BP not achieving target } & $680(59.5 \%)$ \\
\hline \multicolumn{2}{|c|}{ ONLY diastolic BO not achieving target } & $48(4.2 \%)$ \\
\hline \multirow[t]{4}{*}{ Mean systolic BP by age group } & Age 40 and under & $143.8 \mathrm{mmHG}$ \\
\hline & Age 41 to 60 & $145.7 \mathrm{mmHG}$ \\
\hline & Age 61 to 80 & $149.8 \mathrm{mmHG}$ \\
\hline & Age $8 \mathrm{I}$ and older & $151.6 \mathrm{mmHG}$ \\
\hline \multirow[t]{4}{*}{ Mean diastolic BP by age group } & Age 40 and under & $91.6 \mathrm{mmHG}$ \\
\hline & Age 41 to 60 & $87.6 \mathrm{mmHG}$ \\
\hline & Age 61 to 80 & $81.0 \mathrm{mmHG}$ \\
\hline & Age $8 \mathrm{I}$ and older & $78.5 \mathrm{mmHG}$ \\
\hline
\end{tabular}

Table 1 provides details of the 1142 patients who had not achieved target levels of blood pressure according to the last three chart blood pressure measurements. Overwhelmingly it was the systolic blood pressure that was not under control. Eighteen percent of the patients have diabetes. All patients were on at least one medication. As expected, the mean systolic $\mathrm{BP}$ increased with age; the mean systolic BP is above target for all age groups. Somewhat unexpectedly the mean diastolic BP decreased with age.

Table 2 provides details on the degree to which targets were not achieved. Most of the patients who had not achieved target according to our criteria were within 10 mmHg of the recommended targets.

Table 3 shows the results of 436 patients who completed 24 hour ABPM. Isolated systolic blood pressure based on measurements recorded from the physician charts best predicted elevated mean daytime blood pressures and but only with a maximum positive predictive value of $70 \%$.

\section{Discussion}

We found 1142 (35\%) of the 3284 patients who had a diagnosis of essential hypertension were uncontrolled based on blood pressures recorded in the chart. This does not mean that $65 \%$ of the hypertension patients had 
Table 2: Mean and ranges of systolic and diastolic blood pressures that were above treatment targets

\begin{tabular}{|c|c|c|c|c|c|}
\hline & $\begin{array}{c}\text { Mean (SD) of systolic BPs } \\
\text { above target }\end{array}$ & $\begin{array}{c}\text { Number (\%) between } \\
130-139 \mathrm{mmHg}\end{array}$ & $\begin{array}{l}\text { Number (\%) between } \\
140-149 \mathrm{mmHg}\end{array}$ & $\begin{array}{l}\text { Number (\%) between } \\
150-159 \mathrm{mmHg}\end{array}$ & Number (\%) $160+\mathrm{mmHg}$ \\
\hline \multirow{2}{*}{$\begin{array}{l}\text { Considered out of control } \\
\text { due to elevated systolic } \\
\text { pressure }\end{array}$} & $148(I I)$ & $209(18.3 \%)$ & $462(40.5 \%)$ & $288(25.2 \%)$ & $161(14.1 \%)$ \\
\hline & $\begin{array}{c}\text { Mean (SD) of diastolic BPs } \\
\text { above target }\end{array}$ & $\begin{array}{l}\text { Number (\%) between } 80- \\
89 \mathrm{mmHg}\end{array}$ & $\begin{array}{l}\text { Number (\%) between } 90- \\
99 \mathrm{mmHg}\end{array}$ & $\begin{array}{l}\text { Number (\%) between } \\
100-109 \mathrm{mmHg}\end{array}$ & Number (\%) $110+\mathrm{mmHg}$ \\
\hline $\begin{array}{l}\text { Considered out of control } \\
\text { due to elevated diastolic } \\
\text { pressure }\end{array}$ & $83(8.6)$ & $506(44.3 \%)$ & $232(20.3 \%)$ & $20(1.8 \%)$ & $3(0.3 \%)$ \\
\hline
\end{tabular}

Table 3: Chart blood pressures as predictors of daytime mean blood pressures on $24 \mathrm{hr}$ ABPM

\begin{tabular}{|c|c|c|c|c|}
\hline Predictor & $\begin{array}{l}\text { Number(\%) with elevated } \\
\text { daytime mean systolic on } 24 \\
\text { hour ABPM }\end{array}$ & $\begin{array}{l}\text { Number(\%) with elevated } \\
\text { daytime mean diastolic on } 24 \\
\text { hour ABPM }\end{array}$ & $\begin{array}{l}\text { Number(\%) with daytime } \\
\text { elevation of either systolic or } \\
\text { diastolic on } 24 \text { hour ABPM }\end{array}$ & $\begin{array}{l}\text { Number(\%) with daytime } \\
\text { elevation of both systolic and } \\
\text { diastolic on } 24 \text { hour ABPM }\end{array}$ \\
\hline $\begin{array}{l}\text { Elevated systolic blood pressure } \\
\text { only on chart }(N=268)\end{array}$ & 185 (69\%) & $56(20.9 \%)$ & $188(70.1 \%)$ & $53(19.8)$ \\
\hline $\begin{array}{l}\text { Elevated diastolic blood } \\
\text { pressure only on chart }(\mathrm{N}=15)\end{array}$ & $7(46.7 \%)$ & $4(26.7)$ & 7 (46.7) & $4(26.7 \%)$ \\
\hline $\begin{array}{l}\text { Both systolic and diastolic BP } \\
\text { elevated on the chart }(N=\mid 52)\end{array}$ & 99 (65.1\%) & $55(36.2)$ & $104(68.4)$ & 50 (32.9\%) \\
\hline
\end{tabular}

achieved target. Apart from being removed from consideration by eligibility criteria not related to blood pressure, there were also a number of patients who refused to participate very early in the process and some who were removed from the list by the physician who felt participation in the study was not appropriate for the patient. However we can say that at least 35\% had not achieved target and it is likely that the true number is higher.

It is the failure to achieve the office systolic blood pressure targets that resulted in the majority of patients being classified as "out of control". Elevated systolic blood pressure was present in nearly $96 \%$ of patients and for nearly $60 \%$ this was the only criteria for that classification. Isolated elevation of the diastolic pressure accounted for only $4.3 \%$ of people being labeled "out of control". These results may reflect the greater importance placed on control of diastolic blood pressure; or perhaps antihypertensive medication are more effective at lowering diastolic blood pressure; or given that only $70 \%$ of patients with elevated systolic blood pressure on their charts actually met the criteria for unsatisfactory control by the 24 hour ABPM, perhaps what we are seeing is a large white coat effect.

In addition to the white coat effect as a partial explanation both for the proportion of people labeled as "out of control" and for the rather poor association between the blood pressure levels on the chart and 24 hour ABPM, we should also note that the degree of "out of control" does not appear to be large. Is a $35 \%$ "out of control" rate too high if the degree of "out-of-control" is small? If we believe the data on which the target of $<140 / 90 \mathrm{mmHg}$ is based then there is a continuing beneficial effect for the patient down to that level. The decision to treat more aggressively is one made by dialogue between the patient and his/her physician.

What this study does show is that we may be mislabeling patients as "out of control" if we use only the physicians' office measurements. Nearly $30 \%$ of our patients who were eligible for the study based on the chart blood pressures had to be excluded after the 24 hour ABPM. Assessing blood pressure control and hence making decisions about medication dosages might be better done with 24 hour ABPM rather than relying on measurements in physician's offices. However this would be expensive and a less expensive method needs to be found. One possible method is the use of automated machines in doctors' offices that take multiple (ie 5 or 6 ) readings automatically with the patient alone in a quiet room.

\section{Conclusions}

Based on abstraction of physician blood pressure measurements recorded in patients' charts, at least 35\% of hypertensive patients in the family physicians offices in 
Kingston, Ontario Canada are not treated to recommended targets. This is primarily due to lack of adequate control of systolic hypertension. However when these patients subsequently have a 24 hour ABMP performed, only $70 \%$ are actually uncontrolled. This gap most likely represents a white coat effect and suggests that when defining hypertension treatment success rates we should be using methods that do not involve the measurement of blood pressure by a physician or even the presence of a physician.

\section{List of abbreviations}

$\mathrm{ABPM}=$ ambulatory blood pressure monitor

HBPM = home blood pressure monitor

ISM = Intensive scheduled management

\section{Competing interests}

None declared.

\section{Authors' contributions}

All authors have reviewed and approved the text of the manuscript. All authors contributed to 1) the conception and design or analysis and interpretation AND 2) the initial drafting or critical revision of the content.

\section{Acknowledgements}

This study is being funded by a grant from the Heart and Stroke Foundation of Ontario, Canada

\section{References}

I. Joffress MR, Ghadirian P, Fodor JG, Petrasovits A, Chockalingham A, Hamet P: Awareness, treatment, and control of hypertension in Canada. Am J Hypertens 1997, 10:1097-I I02.

2. Pavlik VN, Hyman Dj: How well are we managing and monitoring high blood pressure? Curr Opin Nephrol \& Hypertens 2003, 1 2:299-305.

3. He FJ, MacGregor GA: Cost of poor blood pressure control in the UK: 62,000 unnecessary deaths per year. J Hum Hypertens 2003, I 7:455-457.

4. Kannel WB: Blood pressure as a cardiovascular risk factor: prevention and treatment. JAMA 1996, 275(20): I57|-I576.

5. Seddon ME, Marshall MN, Campbell SM, Roland MO: Systematic review of studies of quality of clinical care in general practice in the UK, Australia, and New Zealand. Qual Health Care 200I, 10:152-158.

6. Amar J, Chamontin B, Genes N, Cantet C, Salvador M, Cambou JP: Why is hypertension so frequently uncontrolled in secondary prevention? J Hypertens 2003, 2 I : I I99- I 205.

7. Palatini P, Frigo G, Bertolo O, Roman E, Da Corta R, Winnicki M: Validation of the A\&D TM-2430 device for ambulatory blood pressure monitoring and evaluation of performance according to subjects' characteristics. Blood Press Monit 1998, 3(4):255-260.

\section{Pre-publication history}

The pre-publication history for this paper can be accessed here:

http://www.biomedcentral.com/1471-2261/4/2/prepub

\section{Publish with Biomed Central and every scientist can read your work free of charge}

"BioMed Central will be the most significant development for disseminating the results of biomedical research in our lifetime. "

Sir Paul Nurse, Cancer Research UK

Your research papers will be:

- available free of charge to the entire biomedical community

- peer reviewed and published immediately upon acceptance

- cited in PubMed and archived on PubMed Central

- yours - you keep the copyright 